\title{
Combat Posttraumatic Stress Disorder and Chronic Pain
}

\author{
Braš Marijana ${ }^{1}$, Ana Havelka Meštrović ${ }^{2}$, Mladen Havelka ${ }^{3}$, \\ Morana Bilic ${ }^{3}$, Zoran Lončar ${ }^{4}$ \\ ${ }^{1}$ Department of Psychiatry, University Hospital Zagreb, Zagreb, Croatia; \\ ${ }^{2}$ Department of Psychiatry, University Hospital Dubrava, Dubrava, Croatia; \\ ${ }^{3}$ Department of Health Psychology, University of Applied Health Studies, Zagreb, Croatia; \\ ${ }^{4}$ Department of Traumatology, University Hospital Zagreb, Zagreb, Croatia. \\ Email: mladen.havelka@zvu.hr \\ Received May 26 $6^{\text {th }}, 2011$; revised July $4^{\text {th }}, 2011$; accepted August $8^{\text {th }}, 2011$.
}

\begin{abstract}
Objective: chronic post-traumatic stress disorder (PTSD) is commonly accompanied by depression and anxiety as comorbidity. The psychological states, such as depression and anxiety, can increase pain symptoms. A number of recent research results have shown that chronic post-traumatic stress disorder and chronic pain frequently co-occur and similar mechanisms have been identified that sustain both conditions. Method: the data were collected from medical records of 184 Croatian war veterans diagnosed with chronic PTSD and chronic pain as co-morbid condition. On the basis of medical records, interviews and different types of self-assessment questionnaires the inter-relationship between chronic pain and chronic PTSD was analysed. PTSD was assessed by CAPS (Clinical Administered Posttraumatic Scale) and M-PTSD (Mississippi Scale for combat PTSD), whereas pain was measured by Melzack-McGill Pain Questionnaire - short form (MPQ-SF) and Visual Analogue Scale (VAS). Results: the combat veterans with PTSD reported in descending order the following: pain in the head, back pain, widespread pain and limb pain. The patients with chronic PTSD had significantly higher total pain scores as well as affective and sensory pain components when compared to the patients without PTSD. Anxiety and depression were also highly correlated with pain. The relation between pain severity and depression was mediated by the severity of PTSD. Conclusion: our findings are directed towards the need for multidisciplinary approach in the treatment of patients with chronic PTSD and co-morbid chronic pain, which will optimize treatment and result in more cost-effective care.
\end{abstract}

Keywords: Chronic Pain, Posttraumatic Stress Disorder, Melzack-McGill Pain Questionnaire, Depression, Anxiety

\section{Introduction}

Posttraumatic stress disorder (PTSD) includes psychological imbalance and neurophysiologic dysfunctions resulting in behaviour changes that significantly affect the relation between an individual and his social and natural environment. Clinically, the disorder is manifested through the triad of symptoms, i.e. repetition, avoidance and excitation, commonly accompanied by anxiety and depression. Based on the IASP (International Association for the Study of Pain) pain is defined as a discomforting sensory and emotional experience related to the actual or possible tissue damage or mere description of such a damage (Keefe et al., 2004). Pain can appear even when there is no tissue injury, it can be experienced as intense in minor injuries, or can be mild upon sustaining massive injuries. The influence of psychological factors on pain experience is referred to as psychogenic pain, the pain that should by no means be differentiated from the so-called "real" pain, i.e. the one caused by injuries or pathological processes in tissues. Significant correlation has been found between chronic pain and psychological disorders. The model of the development of chronic pain is similar to the model that describes the CNS plasticity in its response to psychological trauma and is therefore strongly related to chronic PTSD (Otis et al., 2003). Similar to chronic PTSD, there is an increasing evidence indicating the patient's hereditary predisposition to the development of chronic pain, which, following the continuing and strong nociceptive stimuli from the periphery resulting in neuroplastic changes in the basal ganglia and the cortex, can also serve as a model for the development of chronic posttraumatic stress disorder. The most recent studies have shown that pain is one of the most common symptoms in PTSD patients, regardless of the nature of traumatic experience. Sudden change in life habits upon sustaining a trauma, together with the possible posttraumatic reaction, can signifycantly affect the ability of coping with pain. Geuze et al. in their study of 12 veterans with PTSD and 12 veterans without PTSD find diminished sensitivity to pain in PTSD patients (Geuze et al., 2007), specifically in terms of altered processing of pain in brain regions related to affective and cognitive pain processing, e.g. the insula, the hypocampus, the amygdala and the ventrolateral prefrontal cortex. Other studies have reported about similar findings (Nemeroff et al., 2006; Lanius et al., 2003; Shin et al., 2005). However, there are also studies showing that in individuals with borderline personality structure the sensitiveity to pain is altered, although not in PTSD patients (Schmahl et al., 2008). Defri et al. have recently reported about the first systematic and quantitative evaluation of the perception of pain in PTSD (Defrin et al., 2008). The PTSD patients showed higher levels of chronic pain, much more intense chronic pain, and greater number of painful regions in the body than the control study group. The severity of PTSD symptoms correlated with the severity of painful symptoms. The pain threshold in PTSD patients was higher than in the control and anxiety patient groups, but the pain stimulus above the pain threshold was experienced much more intensely than by other study group subjects. The question is raised here whether it is about the altered sensory processing or the way in which the PTSD patients interpret and respond to painful stimuli. The 
extent of PTSD in our study patients was measured by M-PTSD questionnaire. For reasons of assessment of correlation between the PTSD extent, pain and other co-morbid states, the patients were divided into two groups: the group with strongly expressed PTSD (above the cut-off point in the MPTSD questionnaire), and those without pain, although all of the patients have been for several years psychiatrically treated for PTSD. The assumption is that in a certain number of Croatian war veterans the therapy has resulted in diminishing of symptoms and the fact has also been taken into consideration that the PTSD is a chronic disorder with exacerbations and that not all the patients are in the same mental states at the same time. Other studies have also shown that the PTSD symptoms occur more often in individuals with headaches when compared with the general population, assuming that PTSD is a risk factor for chronic headache (Peterlin et al., 2008). Low back pain is particularly interesting, since many studies have provided evidence of how psychological variables affect the low back pain sensations. In a study of low back pain patients six years after their traffic accident it was observed that pain did not correlate with the severity of sustained injury and socio-demographic factors, but rather with the presence of PTSD. The conclusion was that the psycho-social factors rather than the physical ones, were predictors of symptomatic low back pain following major physical trauma (Harris et al., 2007). Besides, the correlation between pain in the whole body and the fibromyalgia symptom is of particular interest, since in a significant number of patients with fibromyalgia the presence of traumatic stressors and PTSD symptoms has been found (Näring et al., 2007). The studies report about three basic dimensions of anxiety sensitivity: fear that the anxiety reactions will be publicly noticed; fear from losing cognitive control; and fear from somatic sensations. It has been shown that these are increased in PTSD patients (Taylor et al., 2001), but only in a limited number of chronic pain patients. It has also been found that the severity of anxiety sensitivity is positively correlated with the severity of PTSD symptoms (Fedor et al., 2000). The aim of our study was to explore the link between PTSD and chronic pain and comorbid diagnosis, such as depression and anxiety.

\section{Method}

\section{Subjects}

The total number of 184 patients participated in the study. All patients were diagnosed with chronic war induced PTSD based on DSM-IV and ICD-10. They were treated at Osijek Clinical Hospital, Department of Psychiatry and all of them also suffered from co-morbid chronic pain, as defined according to the IASP criteria (International Association for the Study of Pain). The study subjects with the diagnosis of war induced PTSD were treated from 2004 to 2006. In their medical history they all reported direct participation in military activities of Croatian Army, at least for three continuous months, and repeated exposure to life threatening situations or wounding during the 1991-1995 war. In the selection of study subjects the following painful syndromes were taken into consideration: chronic primary pain in the head, chronic lumbo-sacral syndrome, chronic cervico-brachial syndrome, chronic peripheral neuralgia, polyneuropathy, and generalized pain in the whole body. The sample was randomised by random selection of patients of both sexes who signed the informed consent for participation in the study. There were 21 (11.41\%) female and 163
$(88.58 \%)$ male study subjects. The average age of the study subjects was 40.54 years, while most of the subjects were 39 years of age. The average age for male study subjects was 40.71 years and it was 39.24 years for the female study subjects.

\section{Study Objectives}

The principal study objective was to define the relation between chronic PTSD and its co-morbid diagnoses, i.e. depresssion and anxiety, and co-morbid manifestations of chronic pain, like for instance lower back pain, pain in the cervical spine, pain in the head, generalised pain in the entire body and pain in the extremities.

\section{Methods}

Through the psychiatric interview, questionnaires and selfassessment scales information was collected about different categories of experience and other characteristics that could contribute to the development of clinical manifestations of PTSD and chronic pain. The principal characteristics of PTSD clinical manifestations and chronic pain are the following: increased sensitivity and excitability of CNS to external stimuli, stressor features, socio-economic factors following the trauma, social support, family support, occupational status (employed or retired), sex, age when traumatic event was experienced. It has been assumed that each of the above factors can affect the increased or decreased risk for the development of chronic PTSD and chronic pain.

The data were collected retrospectively, except those concerning PTSD symptomatology, actual level of anxiety, depresssion and subjective pain experience.

\section{Instruments}

1) Specialized structured non-standardized questionnaire for collection of data on socio-economic status, psychiatric therapy and duration and treatment of chronic pain.

2) Detailed psychiatric examination of war veterans and analysis of the available medical records for the purpose of diagnosing the war induced PTSD based on ICD - 10 (International Classification of Diseases) for mental disorders; M-PTSD questionnaire (Keane, Caddell, \& Taylor, 1986 Mississippi PTSD questionnaire) for the assessment of the level of PTSD symptoms. The M-PTSD measures the degree of PTSD expression following traumatic experience and it consists of 36 Likert type items.

3) The state of anxiety and its characteristics were measured by State Trait-Anxiety Inventory Questionnaire (STAI). STAI (Spilerberger, 1977) scale measures the degree of anxiety as a state and anxiety as a personality trait and it contains the total of 40 Likert type items.

4) The assessment of the degree, or level, of depression was made by Beck depression questionnaire (BDI-Beck Depression Inventory), containing 21 questions answered only by one of the 4 offered answers. The instrument contains items that refer to symptoms, such as hopelessness and irritability, the feeling of guilt or punishment, and also the physical symptoms (e.g. fatigue, weight loss, diminished interest in sex, etc.).

5) The assessment of psycho-pathology by SCL-90 questionnaire (Product Symptom Checklist, Derogatis, 1965) - includes the test that contains 90 Likert type items and is used as a measurement of psychological problems and symptoms of psycho-pathology; for instance, somatisation, obsessive-compulsive disorders, panic attacks, inter-personal sensitivity, de- 
pression, anxiety, hostility, paranoid ideas, psychotic characteristics.

6) The Melzack-McGill Pain Questionnaire was used for the assessment of single components of pain, qualitative description of chronic pain and degree of pain intensity (McGill Pain Questionnaire, MPQ, Melzack, 1975). Today it is one of the most commonly used instruments in pain studies. Besides qualitative and quantitative characteristics of pain, the questionnaire provides insight into the sensory and affective components of subjective pain experience.

\section{Statistics}

Descriptive statistical analysis was made by the method of grouping the obtained data, mean values, dispersion values (standard deviation), correlation coefficients and regression analysis.

\section{Results}

The obtained results showed that the majority of the study subjects $(64.67 \%)$ started noticing their mental disturbances only after the end of the war. Most of them began with the treatment also after the war, although $48 \%$ of the study subjects reported to have experienced some kind of psychological disorders already during the war. The smallest number of patients, i.e. only 17 of them, became aware of the problem and commenced with the treatment for their disorders already during the war. The majority of them were 2 to 3 times hospitalized in psychiatric departments during their treatment. It is interesting to note that the patients have complained of long-term chronic pain; some of them have presented with one painful syndrome and some with more simultaneous painful syndromes; a significant number of patients $(22.8 \%)$ have reported painful sensations in the entire body. These patients are particularly interesting because of neuro-biological and clinical relations between PTSD symptoms, fibromyalgia, chronic fatigue and de pression. Pain in the lumbar spine was reported by $47.28 \%$ of study subjects, pain in the cervical spine by $17.93 \%$, pain in the head by $54.9 \%$ and pain in the limbs by $5.4 \%$ of study subjects.

With regard to the beginning of mental problems the patients are divided into 2 groups. The first group are the patients in whom the disorders started during the war, at some time between 1990 and 1995, and the second group are those in whom the disorders appeared after the war, i.e. between 1996 and
2004. The questions about the beginning and location of chronic pain were treated separately. The patients were also divided into the group in whom the chronic pain started during the war and the group in whom it started after the war.

It may be observed that most of the study subjects (75\%) report the beginning of chronic pain after the war.

Anxiety is small but significant extent related to pain location in the head $(r=0.16 ; p<0.05)$, while the correlation with pain variables is insignificant. The results further show no significant correlation between PTSD and pain location $(\mathrm{p}>0.05)$ (Table 1)

The study results show also statistically significant positive relation between the expression of PTSD and different types of psychological disorders. The more expressed the PTSD symptoms the greater is the tendency toward somato-vegetative disorders $(\mathrm{r}=0.686 ; \mathrm{p}<0.01)$; i.e. the problems pertaining to anxiety $(\mathrm{r}=0,790 ; \mathrm{p}<0.01)$ and depression $(\mathrm{r}=0.806 ; \mathrm{p}<0.01)$ prevail together with obsessive-compulsive $(\mathrm{r}=0.697 ; \mathrm{p}<0.01)$ and phobic disorders $(r=0.643 ; \mathrm{p}<0.01)$. Hypersensitivity $(\mathrm{r}=$ $0,658 ; \mathrm{p}<0.01)$, paranoid $(\mathrm{r}=0.542 ; \mathrm{p}<0.01)$, and hostile tendencies $(r=0.742 ; \mathrm{p}<0.01)$ increase with the increased intensity of disorders pertaining to PTSD syndrome. Sleeping difficulties are also associated with increased intensity of PTSD syndrome $(\mathrm{r}=0.553 ; \mathrm{p}<0.01)$.

Affective pain is significantly negatively correlated with the pain in the whole body $(\mathrm{r}=-0.21 ; \mathrm{p}<0.05)$, and insignificantly with other pain location variables.

As shown in the above table, sensory pain is significantly negatively correlated with the location of pain in the whole body $(\mathrm{r}=-0.23 ; \mathrm{p}<0.05)$, and insignificantly with all other variables of pain location (Table 2 ).

As shown in Table 3. The predictor criteria for "sensory pain", the "pain in the whole body" has been found as the best predictor $(\mathrm{B}=-6.66 ; \mathrm{p}<0.05)$, followed by depression $(\mathrm{B}=$ $0.26 ; \mathrm{p}<0.05)$. The applied set of predictors accounts for $31.4 \%$ of criteria variance $\left(\mathrm{R}^{2}=0.314 ; \mathrm{F}=3.061, \mathrm{p}<0.05\right)$.

In defining the predictor criteria for the "affective pain", pain in the whole body $(\mathrm{B}=-2.88 ; \mathrm{p}<0.05)$ and depression ranked highest $(\mathrm{B}=0.13 ; \mathrm{p}<0.05)$ (Table 4$)$. The applied set of predictors accounts for $28.0 \%$ of criteria variance $\left(\mathrm{R}^{2}=0.280 ; \mathrm{F}=\right.$ $2.599, \mathrm{p}<0.05)$. The study subjects reporting about the pain in the whole body also show higher levels of PTSD, depression and anxiety; they also report higher intensity of sensory and affective pain experience and have greater difficulties in social and family relations.

Table 1.

Correlation coefficient between PTSD, anxiety and pain location.

\begin{tabular}{|c|c|c|c|c|c|c|c|}
\hline VARIABLE & $\begin{array}{l}\text { PAIN IN THE } \\
\text { LUMBAR SPINE }\end{array}$ & $\begin{array}{c}\text { PAIN IN THE } \\
\text { CERVICAL SPINE }\end{array}$ & $\begin{array}{l}\text { PAIN IN } \\
\text { THE HEAD }\end{array}$ & $\begin{array}{l}\text { PAIN IN THE } \\
\text { WHOLE BODY }\end{array}$ & $\begin{array}{l}\text { PAIN IN THE } \\
\text { LIMBS }\end{array}$ & (M-PTSD) & $\begin{array}{c}\text { (STAI 1) } \\
\text { ANXIETY } \\
\text { AS A STATE }\end{array}$ \\
\hline PAIN IN THE LUMBAR SPINE & 1.00 & & & & & & \\
\hline PAIN IN THE CERVICAL SPINE & $0.37 *$ & 1.00 & & & & & \\
\hline PAIN IN THE HEAD & -0.02 & $-0.25^{*}$ & 1.00 & & & & \\
\hline PAIN IN THE WHOLE BODY & $-0.48^{*}$ & $-0.25 *$ & $-0.60^{*}$ & 1.00 & & & \\
\hline PAIN IN THE LIMBS & $-0.19 *$ & -0.11 & $0.17 *$ & -0.13 & 1.00 & & \\
\hline (M-PTSD) & -0.03 & -0.07 & 0.15 & -0.14 & -0.08 & 1.00 & \\
\hline (STAI 1) ANXIETY AS A STATE & -0.02 & -0.03 & $0.16^{*}$ & -0.14 & -0.02 & $0.64 *$ & 1.00 \\
\hline
\end{tabular}


Table 2.

Correlation coefficient between affective and sensory pain component (McGill) and its location.

\begin{tabular}{|c|c|c|c|c|c|c|c|}
\hline VARIABLE & $\begin{array}{l}\text { PAIN IN THE } \\
\text { LUMBAR } \\
\text { SPINE }\end{array}$ & $\begin{array}{l}\text { PAIN IN THE } \\
\text { CERVICAL } \\
\text { SPINE }\end{array}$ & $\begin{array}{l}\text { PAIN IN } \\
\text { THE } \\
\text { HEAD }\end{array}$ & $\begin{array}{l}\text { PAIN IN THE } \\
\text { WHOLE } \\
\text { BODY }\end{array}$ & $\begin{array}{l}\text { PAIN IN } \\
\text { THE } \\
\text { LIMBS }\end{array}$ & $\begin{array}{c}\text { (MCGILL) } \\
\text { AFFECTIVE } \\
\text { COMPONENT OF PAIN }\end{array}$ & $\begin{array}{c}\text { (MCGILL) } \\
\text { SENSORY COMPONENT } \\
\text { OF PAIN }\end{array}$ \\
\hline $\begin{array}{l}\text { PAIN IN THE } \\
\text { LUMBAR SPINE }\end{array}$ & 1.00 & & & & & & \\
\hline $\begin{array}{c}\text { PAIN IN THE } \\
\text { CERVICAL SPINE }\end{array}$ & $0.37 *$ & 1.00 & & & & & \\
\hline PAIN IN THE HEAD & -0.02 & $-0.24 *$ & 1.00 & & & & \\
\hline $\begin{array}{l}\text { PAIN IN THE } \\
\text { WHOLE BODY }\end{array}$ & $-0.48^{*}$ & $-0.25^{*}$ & $-0.59^{*}$ & 1.00 & & & \\
\hline PAIN IN THE LIMBS & $-0.18^{*}$ & -0.12 & $0.16^{*}$ & -0.13 & 1.00 & & \\
\hline $\begin{array}{l}\text { (MCGILL) AFFECTIVE } \\
\text { COMPONENT OF PAIN }\end{array}$ & 0.09 & 0.08 & 0.07 & $-0.21^{*}$ & -0.03 & 1.00 & \\
\hline $\begin{array}{l}\text { (MCGILL) SENSORY } \\
\text { COMPONENT OF PAIN }\end{array}$ & 0.03 & 0.09 & 0.11 & $-0.23 *$ & 0.06 & $0.71^{*}$ & 1.00 \\
\hline
\end{tabular}

Note: $* \mathrm{p}<0.05$

Table 3.

Contribution of predictors in the prognosis of "sensory pain" criteria.

\begin{tabular}{cccccc}
\hline PREDICTORS & B & SE & Beta & $\mathrm{t}$ & $\mathrm{p}$ \\
\hline PAIN IN THE LUMBAR SPINE & -2.84 & 2.05 & -0.18 & -1.39 & 0.17 \\
PAIN IN THE CERVICAL SPINE & 0.90 & 2.10 & 0.05 & 0.43 & 0.67 \\
PAIN IN THE HEAD & -3.09 & 2.10 & 0.20 & -1.47 & 0.14 \\
PAIN IN THE WHOLE BODY & -6.66 & 3.15 & 0.36 & -2.12 & $\mathbf{0 . 0 4}$ \\
PAIN IN THE LIMBS & -2.18 & 3.35 & 0.06 & -0.65 & 0.52 \\
PTSD & 0.01 & 0.05 & 0.03 & 0.19 & 0.85 \\
ANXIETY AS A STATE & 0.15 & 0.12 & 0.21 & 1.30 & 0.20 \\
ANXIETY AS PERSONALITY TRAIT & -0.03 & 0.15 & -0.03 & -0.21 & 0.84 \\
DEPRESSION & 0.26 & 0.11 & 0.36 & 2.30 & $\mathbf{0 . 0 2}$ \\
PHYSICAL HEALTH & -0.13 & 0.29 & -0.05 & -0.44 & 0.66 \\
PSYCHOLOGICAL HEALTH & 0.55 & 0.33 & 0.25 & 1.66 & 0.10 \\
SOCIAL RELATIONS & 0.20 & 0.49 & 0.05 & 0.41 & 0.68 \\
ENVIRONMENT & -0.17 & 0.20 & -0.11 & -0.85 & 0.40 \\
\hline
\end{tabular}

Table 4.

Contribution of predictors in the prognosis of "affective pain" criteria.

\begin{tabular}{cccccc}
\hline PREDICTORS & B & SE & Beta & $\mathrm{t}$ & $\mathrm{p}$ \\
\hline PAIN IN THE LUMBAR SPINE & -0.86 & 0.92 & -0.13 & -0.94 & 0.35 \\
PAIN IN THE CERVICAL SPINE & -0.22 & 0.94 & -0.03 & -0.24 & 0.81 \\
PAIN IN THE HEAD & -1.57 & 0.94 & -0.24 & -1.67 & 0.10 \\
PAIN IN THE WHOLE BODY & -2.88 & 1.41 & -0.35 & -2.04 & $\mathbf{0 . 0 4}$ \\
PAIN IN THE LIMBS & -1.59 & 1.50 & -0.10 & -1.06 & 0.29 \\
PTSD & 0.00 & 0.02 & 0.03 & 0.20 & 0.84 \\
ANXIETY AS A STATE & 0.07 & 0.05 & 0.23 & 1.38 & 0.17 \\
ANXIETY AS PERSONALITY TRAIT & -0.07 & 0.07 & -0.16 & -0.99 & 0.32 \\
DEPRESSION & 0.13 & 0.05 & 0.42 & 2.64 & $\mathbf{0 . 0 1}$ \\
PHYSICAL HEALTH & -0.03 & 0.13 & -0.03 & -0.21 & 0.84 \\
PSYCHOLOGICAL HEALTH & 0.09 & 0.15 & 0.10 & 0.62 & 0.53 \\
SOCIAL RELATIONS & 0.13 & 0.22 & 0.08 & 0.58 & 0.56 \\
ENVIRONMENT & 0.00 & 0.09 & 0.00 & 0.02 & 0.99 \\
\hline
\end{tabular}




\section{Discussion}

The patients have presented with long duration of chronic pain; some of them with only one painful syndrome, some with multiple simultaneous painful syndromes, and a significant number of them with pain in the whole body $(22.8 \%)$. The latter ones are interesting for study purposes because of neurobiological and clinical relations between the PTSD symptoms, fibromyalgia, chronic fatigue and depression. The pain in lumbar spine was reported by $47.28 \%$ of study subjects, pain in the cervical spine by $17.93 \%$, headache by $54.9 \%$, and pain in the extremities by $5.4 \%$ of the study subjects. A significant number of our study subjects report about pain in the head, but further research is needed for more thorough analysis of these types of pain. A certain number of studies have shown that PTSD symptoms are more expressed in individual suffering from different types of headaches when compared with the general population. The assumption is that PTSD is a risk factor for chronic headache (Peterlin et al., 2008). As has already been discussed, the assumption of specific interest is that of relation between the pain in the whole body and the symptoms of fibromyalgia, since in a significant number of patients with fibromyalgia the existence traumatic stressors and PTSD symptoms has been (Naring et al., 2007). Another interesting issue is the relation between anxiety as a state, or diagnosed condition, personality traits and PTSD level. By noticing the correlation between the PTSD degree measured by the above described study instruments and anxiety, depression and sensory and affective pain components, it can be concluded that there is a statistically significant correlation between the above tests (Table 4) The significant positive correlations between the degree of PTSD symptoms and anxiety as a personality trait and condition are particularly interesting as it the PTSD degree and sensory and affective pain components. The importance of depression intensity has been noticed in terms of its significant positive correlation with painful experience and degree of PTSD. All of these can be discussed in terms of common vulnerability. In reference literature the term "anxiety sensitivity" is used as a disposing sensitivity for anxiety reactions and fear from the very anxiety symptoms because of belief that they can cause harmful effects (Sharp et al., 2001). Our study results support the model of common sensitivity. With regard to the PTSD relation to pain, depression has proved as an important factor. It is possible that the changes resulting from depression (fatigue, diminished activity, etc.) lead to aggravation and sustaining of symptoms, both of pain and of PTSD, and of a general disability. The obtained results indicate that PTSD does not significantly correlate with any of the pain sites $(p>0.05)$. Anxiety as a state shows low but significant correlation with headache $(\mathrm{r}=0.16 ; \mathrm{p}<0.05)$, and insignificant correlation with other variables. The results have also shown that anxiety as a personality trait does not significantly correlate with any variable of the site of pain $(p>0.05)$. The best predictors of sensory pain criteria have shown to be pain in the whole body $(\mathrm{B}=$ $-6.66 ; \mathrm{p}<0.05)$ and depression $(\mathrm{B}=0.26 ; \mathrm{p}<0.05)$. The employed set of predictors provided for $31.4 \%$ of criteria variance $\left(\mathrm{R}^{2}=0.314 ; \mathrm{F}=3.061, \mathrm{p}<0.05\right)$. The best predictors of affecttive pain criteria have shown to be pain in the whole body $(\mathrm{B}=$ $-2.88 ; \mathrm{p}<0.05)$ and depression $(\mathrm{B}=0.13 ; \mathrm{p}<0.05)$. The employed set of predictors provided for $28.0 \%$ of criteria variance $\left(\mathrm{R}^{2}=0.280 ; \mathrm{F}=2.599, \mathrm{p}<0.05\right)$. Based on our study results it may be seen that the patients with pain in the whole body have greater levels of PTSD, depression, anxiety, experience greater sensory and affective pain and have greater difficulties in their social relations. The correlation mechanisms between depresssive symptoms and the symptoms of PTSD, although interesting and extensively studied, have not yet been fully clarified. (Maruta et al., 1976; Leo, 2005; Arnow et al., 2006; McWilliams et al., 2003). The recent study carried out by Roth et al. has investigated three models of correlation between pain, PTSD and depression. The results indicate the correlation between the symptoms of depression with pain and PTSD. It has also been shown that the PTSD symptoms independently and directly affect the severity of depression and that the degree of depresssion directly and indirectly affects the intensity of pain (Roth et al., 2008). In reference literature the idea of sensitivity to anxiety is usually discussed as a predisposing sensitivity to anxious reactions and fear from the mere symptoms of anxiety, assumeing they might cause damaging effects (Sharp \& Harvey, 2001). Their study shows that there is mutual vulnerability for both disorders and that the symptoms are mutually supported. It is of utmost importance for clinicians to be aware of this fact when treating such patients, no matter in which department or practice they are being treated. There is also a need for physicians who are assessing the PTSD levels in patients to ask them about the presence of painful symptoms (e.g. fibromyalgia or chronic musculoskeletal pain), including the questions about the nature and location of pain and its effects on the activities of daily living. It may simply be done by tests such as McGill's or structured clinical interviews. Furthermore, in centres for the treatment of chronic pain assessment should be made of the possible PTSD symptoms and depression using clinical interview or selfassessment questionnaires. Patients should also be monitored for sensitivity to anxiety and presence of depression. As regards the treatment, it is important to modify the therapeutic protocols in cases where both disorders are present, which is actually supported by the fact that increased use of combined protocols for both disorders can be seen worldwide.

\section{Study Strenghts and Limitations}

One of the main strengths of our study is in the use of data from clinical samples with diagnosed combat PTSD. The samples provide unique opportunity to investigate combat PTSD symptoms and pain related disorders which can co-occur with other comorbidity diagnoses. However, more research is needed to explain the theoretical models of coexistence of the two disorders, and more thoroughly controlled studies to investigate the efficacy of the treatment methods for co-morbid conditions.

Our study is limited by its cross-sectional nature due to which we cannot interfere with causality. Methodological limitations of our study refer to retrospective data collection. The patients were selected from our hospital, implicating that they came by themselves, which might be scientifically limited. Also, the secondary gain motivation and possibility of exaggerated symptoms cannot be excluded because the scales for PTSD meas urement and pain questionnaires are prone to subjectivity.

\section{Conclusion}

Our study results have shown a significant degree of PTSD symptoms to persist in war veterans despite long-term treatment. The relation has been confirmed between the tests used for the assessment of PTSD, anxiety, depression and sensory and affective components of pain, leading to the conclusion that there is statistically significant correlation between all the applied tests. Positive correlation between the PTSD symptom levels and 
anxiety as a personality trait and as a state are of particular interest, and so are the PTSD levels and sensory and affective components of pain. The importance of the intensity of depresssion has been noticed, especially for its significantly positive correlation between pain experience and PTSD level.

There is significant relation between posttraumatic stress disorder and chronic pain syndromes, which in clinical practice occur together with negative interaction in terms of the course, outcome, and treatment of each individual disorder. It is assumed that when compared with acute stressful stimulus the chronic stress disorder has similar pattern of development as does the chronic neuropathic pain in relation to peripheral painful stimulus. The study has confirmed the assumption about the relation between PTSD and chronic pain.

\section{References}

Arnow, B. A., Hunkeler, E. M., \& Blasey C. M. (2006). Comorbid depression, chronic pain, and disability in primary care. Psychosomatic Medicine, 68, 262-268. doi:10.1097/01.psy.0000204851.15499.fc

Beckham, J. C., Moore, S. D., Feldman, M. E, Hertzberg, M. A., Kirby, A. C, \& Fairbank, J. A. (1998). Health status, somatization, and severity of posttraumatic stress disorder in Vietnam combat veterans with posttraumatic stress disorder. American Journal of Psychiatry, $155,1565-1569$.

Bouckoms, A. J. (1999). Chronic pain: Neuropsychopharmacology and adjunctive psychiatric treatment. In J. Rundel, \& M. Wise (Eds.), Textbook of consultation-liaison psychiatry (Vol. 41, pp. 1006-1036). Washington: American Psychiatric Press Inc.

Bryant, R. A., Marosszeky, J. E, Crooks, J., Baguley, I. J., \& Gurka, J. A. (1999). Interaction of posttraumatic stress disorder and chronic pain following traumatic brain injury. Journal of Head Trauma Rehabilitation, 14, 588-594. doi:10.1097/00001199-199912000-00007

Clark, M. R., \& Treisman, G. J. (1991). Pain and depression-An Interdisciplinary patient-centered therapy. Advances in Psychosomatic Medicine, 25, 78-88.

Davidson, J. T., Stein, D. J., Shalev, A. J., \& Yehuda, R. (2004). Posttraumatic stress disorder: Acquisition, recognition, course, and treatment. Journal of Neuropsychiatry and Clinical Neurosciences, 16, 135-147. doi:10.1176/appi.neuropsych.16.2.135

Defrin, R., Ginzburg, K., Solomon, Z., Polad, E., Bloch, M., Govezensky, M., \& Schreiber, S. (2008). Quantitative testing of pain perception in subjects with PTSD - Implications for the mechanism of the coexistence between PTSD and chronic pain. Pain, 138, 450-459. doi:10.1016/j.pain.2008.05.006

Diatchenko, L., Slade, G. D., Nackley, A. G., Bhalang, K., Sigurdsson, A., Belfer, I., Goldman, D., Xu, K., Shabalina, S. A., Shagin, D., Max, M. B., Makarov, S. S., \& Maixner, W. (2005). Genetic basis for individual variations in pain perception and the development of a chronic pain condition. Human Molecular Genetics, 14, 135-143. doi: $10.1093 / \mathrm{hmg} / \mathrm{ddi} 013$

Fedoroff, I. C., Taylor, S., Asmundson, G. J. G., \& Koch, W., J. (2000). Cognitive factors in traumatic stress reactions: Predicting PTSD symptoms from anxiety sensitivity and beliefs about harmful events. Behavioural and Cognitive Psychotherapy, 28, 5-15.

Geuze, E., Westenberg, H. G., Jochims, A., De Kloet, C. S., Bohus, M., Vermetten, E., \& Schmahl, C. (2007). Altered pain processing in veterans with posttraumatic stress disorder. Archives of General Psychiatry, 64, 76-85. doi:10.1001/archpsyc.64.1.76

Harris, I. A., Young, J. M., Rae, H., Jalaludin, B. B., \& Solomon, M. J. (2007). Factors associated with back pain after physical injury: A survey of consecutive major trauma patients. Spine, 32, 1561-1565. doi:10.1097/BRS.0b013e318067dce8

Keefe, F. J., Rumble, M. E., Scipio, C. D., Giordano, L. A., \& Perri, L. M. (2004). Psychological aspects of persistent pain: Current state of the science-Invited comentary. The Journal of Pain, 5, 195-211. doi:10.1016/j.jpain.2004.02.576

Kessler, R. C., Zhao, S., Katz, S. J. (1999). Past-year use of outpatient services for psychiatric problems in the National Co-Morbidity Survey. American Journal of Psychiatry, 156, 115-123.
Lanius, R. A., Williamson, P. C., Hopper, J., Densmore, M., Boksman, K., Gupta, M. A., Neufeld, R. W., Gati, J. S., \& Menon, R. S. (2003). Recall of emotional states in posttraumatic stress disorder: An fMRI investigation. Biological Psychiatry, 53, 204-210. doi:10.1016/S0006-3223(02)01466-X

Leo, R. J. (2005). Chronic pain and comobid depression. Current Treatment Options in Neurology, 7, 403-412. doi:10.1007/s11940-005-0032-0

Maruta, T., Swanson, D. W., \& Swenson, W. M. (1976). Pain as a psychiatric symptom: Comparison between low back pain and depression. Psychosom, 17, 123-127.

McWilliams, L. A., Cox, B. J., Enns, M. W. (2003) Mood and anxiety disorders associated with chronic pain: An examination in a nationally representative sample. Pain, 106, 127-133. doi:10.1016/S0304-3959(03)00301-4

Melzack, R., \& Casey, K. (1968). The skin senses (pp. 423-439). Springfield, IL: Charles C. Thomas.

Näring, G. W., Van Lankveld, W., \& Geenen, R. (2007). Somatoform dissociation and traumatic experiences in patients with rheumatoid arthritis and fibromyalgia. Clinical and Experimental Rheumatology, 25, 872-877.

Nemeroff, C. B., Bremner, J. D., Foa, E. B., Mayberg, H. S., North, C. S., \& Stein, M. B. (2006). Posttraumatic stress disorder: A state-ofthe-science review. Journal of Psychiatric Research, 40, 1-21. doi:10.1016/j.jpsychires.2005.07.005

Otis, J. D., Keane, T. M., \& Kerns, R. D. (2003). An examination of the relationship between chronic pain and post-traumatic stress disorder. Jorunal of Rehabilitation Research and Development, 40, 397-406. doi:10.1682/JRRD.2003.09.0397

Peterlin, B. L., Tietjen, G., Meng, S., Lidicker, J., \& Bigal, M. (2008). Post-traumatic stress disorder in episodic and chronic migraine. Pain in the Head, 48, 517-522. doi:10.1111/j.1526-4610.2008.00917.x

Roth, R. S., Geisser, M. E., Bates, R. J. (2008). The relation of post-traumatic stress symptoms to depression and pain in patients with accident-related chronic pain. Pain, 9, 588-596. doi:10.1016/j.jpain.2008.01.333

Salomons, T. V., Osterman, J. E., Gagliese, L., \& Katz, J. (2001). Pain flashbacks in posttraumatic stress disorder. Clinical Journal of Pain, 8, 231-234.

Schmahl, C., Meinzer, M., Zeuch, A., Fichter, M., Cebulla, M., Kleindienst, N., Ludascher P., Steil, R., \& Bohus, M. (2008). Pain sensitivity is reduced in borderline personality disorder, but not in posttraumatic stress disorder and bulimia nervosa. World Journal of Biological Psychiatry, 29, 1-8. doi:10.1080/15622970701849952

Shalev, A. Y., Orr, S. P, \& Peri, T. (1992). Physiological responses to loud tones of Israeli post-traumatic stress disorder patients. Archives of General Psychiatry, 49, 870-875.

Sharp, T. J., \& Harvey, A. G. (2001). Chronic pain and posttraumatic stress disorder: Mutual maintenance? Clinical Psychology Review, 21, 857-877. doi:10.1016/S0272-7358(00)00071-4

Shin, L. M., Wright, C. I., Cannistraro, P. A., Wedig, M. M., McMullin, K., Martis, B., Macklin, M. L., Lasko, N. B., Cavanagh, S. R., Krangel, T. S., Orr, S. P., Pitman, R. K., Whalen, P. J., \& Rauch, S. L. (2005). A functional magnetic resonance imaging study of amygdala and medial prefrontal cortex responses to overtly presented fearful faces in posttraumatic stress disorder. Archives of General Psychiatry, 62, 273-281. doi:10.1001/archpsyc.62.3.273

Stein, M. B., McQuaid, J. R., \& Pedrelli, P. (2000). Post-traumatic stress disorder in the primary care medical setting. General Hospital Psychiatry, 22, 261-269. doi:10.1016/S0163-8343(00)00080-3

Symreng, I., \& Fishman, S. M. (2004). Anxiety and pain. Pain Clinical Updates, 12, 12-13.

Taylor, S., Fedoroff, I., Koch, W. J., Thordarson, D. S., Fecteau, G., \& Nicki, R. M. (2001). Posttraumatic stress disorder arising after road traffic collisions: Patterns of response to cognitive-behavior therapy. Journal of Consulting and Clinical Psychology, 69, 541-551. doi:10.1037/0022-006X.69.3.541

Wallace, J., \& Panch, G. (2001). Pain clinic, a new role for psychiatrists. Psychiatric Bulletin, 25, 473-474. doi:10.1192/pb.25.12.473

Yehuda, R., Schmeidler, J., Wainberg, M., Binder-Brynes, K., \& Duvdevani, T. (1998). Vulnerability to posttraumatic stress disorder in adult offspring of Holocaust survivors. American Journal of Psychiatry, 155, 1163-1171. 